\title{
The problem of architectural complexes' restoration in modern conditions
}

\author{
Irina Mayatskaya* and Svetlana Yazyeva \\ Don State Technical University, 344022, Rostov-on-Don, Russia
}

\begin{abstract}
Laser scanning is a modern method of obtaining spatial data. It is possible to get an exact three-dimensional digital copy of the scanned object using this method. It is necessary to preserve the monuments of architecture, restore the complexes of unique structures. This direction in architecture which allows restoring and preserving buildings of architectural heritage is relevant. The use of digital technology and innovation is making the recovery process more efficient. It is necessary to widely introduce three-dimensional modeling methods into practice.
\end{abstract}

\section{Introduction}

Architectural heritage restoration is one of the most important problems in the modern world. It is necessary to preserve architectural monuments, restore the internal space and restore the facades of unique structures [1-4]. Digital technology and innovation can be supportive in this direction more efficiently. Methods of three-dimensional modeling should be introduced into practice at the present time. With this computer technology it becomes possible to measure an architectural structure more accurately, create digital 3D models for future restoration with updated data on external damage, internal defects, and the object's features.

Many monuments of world architecture have been destroyed as a result of recent military conflicts and terrorist attacks (Fig. 1). Numerous objects of historical and cultural heritage were lost in Iraq, Afghanistan, Syria, Cambodia, Libya, and some monuments and structures have disappeared irretrievably [5-10]. The huge Buddha statues in the Afghan Bamiyan Valley had survived for 15 centuries, but were destroyed in just two weeks (Fig. 2), although these statues survived wars, the invasion of Genghis Khan, the Islamization of Afghanistan.

Many architectural complexes are included in the UNESCO World Cultural Heritage List. The governments of these countries face the task of preserving and restoring, but the world community should be supportive as well [11-13]. I would like to note the efforts of the peoples of Syria in the restoration of destroyed and damaged architectural complexes, which are trying to preserve and revive the greatness of the world's masterpieces of the country's ancient architecture, despite the political and economic difficulties.

\footnotetext{
* Corresponding author: irina.mayatskaya@mail.ru
} 


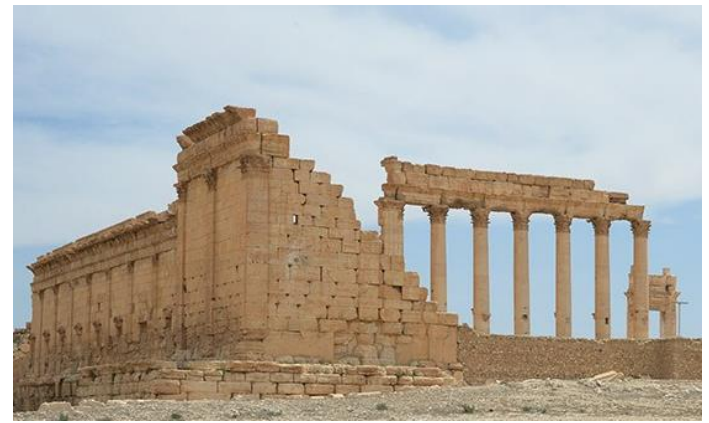

Fig. 1. Temple of Bel in the historical part of Palmyra (Syria).

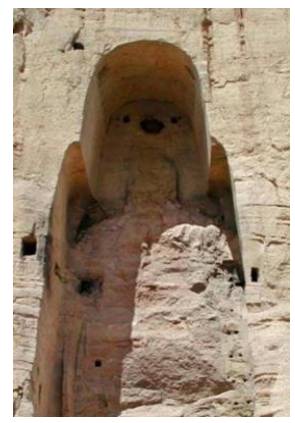

Fig. 2. Statue of Buddha, Bamiyan after destruction (Afghanistan).

Digital technology and innovation can help in rebuilding. It is necessary to create a library of 3D models of the world architectural heritage. Architecture creates a material and spiritual environment in which a person is a part of the whole world. The destruction of the architectural heritage leads to national identityerasure. This is very dangerous for the peace and culture preservation on the planet. Restoration of architectural complexes is an urgent problem in the world.

\section{Architectural heritage - a problem of destruction and restoration}

For many centuries, the world's architectural heritage has been destroyed during armed conflicts as a result of religious fanaticism and natural impact. In the second half of the 20th century and at the beginning of the 21 st century, the question about the preservation of the world cultural heritagewhich were destroyed as a result of hostilities in Iraq, Syria, Libya, Yugoslavia and other countries, arose [5-10, 14].

In 2015, terrorists took over the city of Palmyra, which ancient ruins are one of six UNESCO World Heritage Sites in Syria. They bombed the Baal-Shamin temple, the Bela temple and demolished the statue of the "Lion Allat" (Fig. 1.3). The Syrian Arab Republic has lost the Arc de Triomphe in ancient Palmyra, which was the hallmark of Syria (Fig. 4). And this is only in one region of the country. Efforts are now being made to restore Palmyra, since these architectural complexes are the property of all mankind. But there are many lost monuments in Iraq, Mosul, Syria, and Afghanistan (Fig. 5-7). In the 21st century, the issue of protecting unique structures in the world from their destruction by terrorists has arisen. 15 years ago, on February 26, 2001, two giant Buddha statues in Afghanistan were destroyed. This was the first demonstrative action for the destruction of monuments in the new millennium. UNESCO attempts to preserve this cultural heritage have not led to the restoration of the lost statues in Buddhist monasteriesyet. While on the site of the destroyed statue, its image is being projected in the form of a hologram.

A unique building in Afghanistan is the Dar al-Aman Palace, which was built at the beginning of the 20th century (Fig. 7). After great fire in 1969, the building was reconstructed. But at the end of the 20th century and at the beginning of the 21 st century, it was again destroyed in the course of hostilities and the structure suffered serious damage. The restoration process of the palace started in 2016. In 2019, the palace was completely renovated to commemorate the 100th anniversary of Afghanistan independence, which took place on 19 August 2019. 

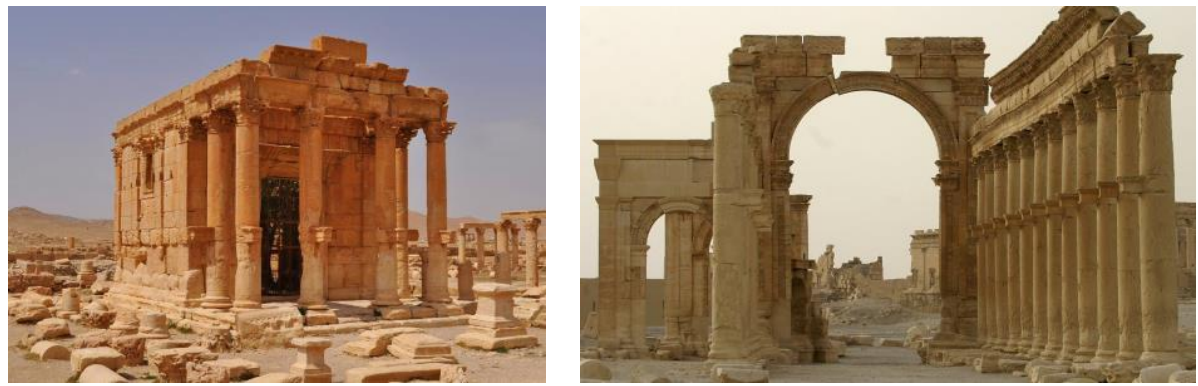

Fig. 3. Temple Baal Shamin in Palmyra (Syria).

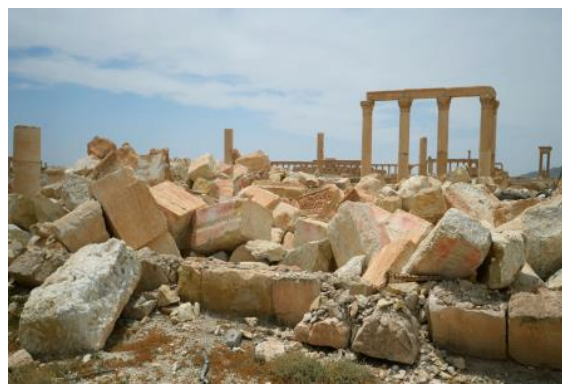

Fig. 5. Destroyed temples in Palmyra (Syria).
Fig. 4. Arc de Triomphe in Palmyra (Syria).

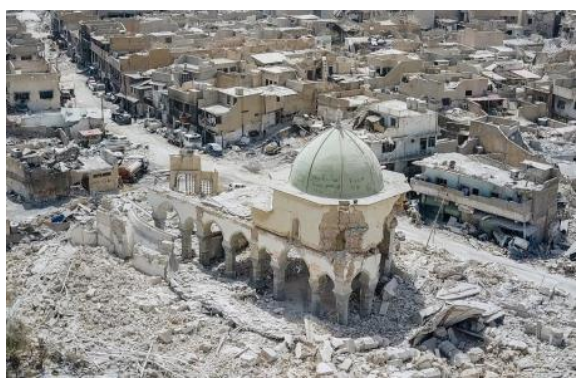

Fig. 6. The destroyed historical center of the city of Mosul (Iraq).

In Afghanistan, the remains of fortifications have been preserved, for example, the fortifications of Herat. The great cathedral mosque in Herat in the middle of the last century also underwent a large-scale restoration - the walls, decor and tiles were restored. UNESCO awarded the prize to ancient Herat - the current administrative center of the Afghan province of the same name. The government is currently blocking a highway with concrete barriers that could collapse the foundations of minarets and mosques in Herat, and is making a project for a bypass.

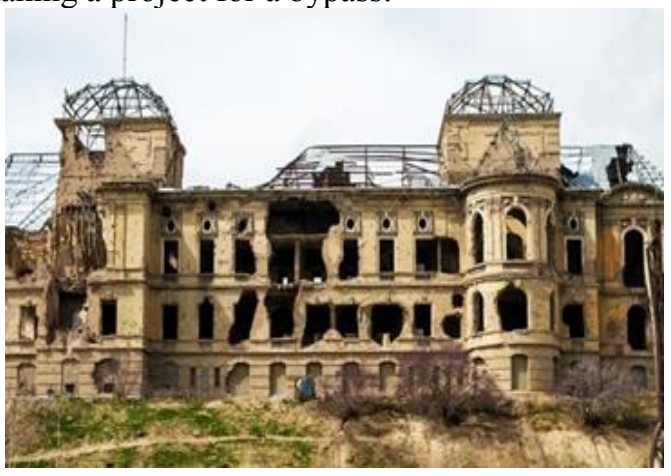

Fig. 7. Dar al-Aman Palace(Afghanistan).

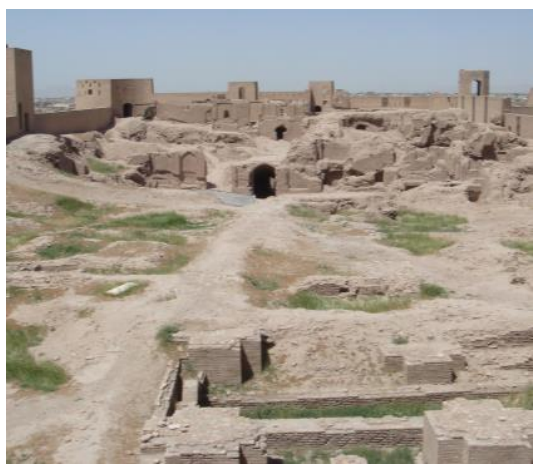

Fig. 8. Herat Fortifications (Afghanistan).

The International Charter for the Conservation and Restoration of Historic Monuments and Sites (Venice, 1964) is aimed more at the conservation of monuments and restoration should be carried out only in exceptional cases. But this is unacceptable in modern conditions, since many monuments of world architecture are in need of restoration. The 
future generation should know its history, including the world heritagearchitectural monuments perception. But it should be noted that the Venice Charter became the first international agreement in the field of the protection of historical heritage, having a significant impact on the solution of issues related to the protection of historical and cultural monuments in Europe and Russia.

In addition to protecting the architectural heritage, it is necessary to restore destroyed structures, applying the principle of restorationreliability. The opinions of experts on the advisability of restoring destroyed monuments vary. Some believe that restoring monuments with destruction in more than $50 \%$ is a "remake" that has no scientific value. But these structures are worth being seen and admired. After World War II, many historical monuments were almost completely destroyed and then restored [15]. And now we are these unique structures. The incredibly beautiful amber room was donated by the Prussian king William I as a diplomatic gift to Peter I in 1716. In 1770 the room was installed in the Catherine Palace in Tsarskoe Selo. But during the Great Patriotic War, the amber room was lost. The reconstruction of the amber room in the Catherine Palace has been going on for over 20 years. It has been fully restored using Kaliningrad amber. Although this is contrary to the principles of restoration in accordance with the international charter for the conservation and restoration of monuments and places of interest. But we can see it, admire the craftsmen and restorers'skills.

Most often, the restoration of architectural monuments takes place using the fragments of the structure found in the ruins and preserved until the start of work. But there has recentlybeen a restoration of the architectural heritage that was previously renovated. This concerns the restoration of historical buildings in St. Petersburg and Moscow $[14,15]$. According to historical documents, they restore not only the general appearance of buildings to destruction, but also reconstruct a number of elements that were lost or distorted before the war.

\section{3D objects scanning}

Laser scanning gives an opportunity to create a detailed 3D model of an object. This makes it possible to electronically store the detailed information about an architectural structure, taking into account the relief of the territory. In this case, the information obtained can be further used in various computer programs for planning reconstruction, repair and construction work. Modern instruments create the data systems that are compatible with Autodesk, AVEVA, AutoCAD, Intergraph and other digital design tools.

Due to its versatility and high degree of measurement processesautomation, the laser scanner is a tool for the restoration of destroyed and reconstructed structures. Fig. 9 shows one of the laser scanners, which makes it possible to quickly obtain data with great accuracy. The operation of the laser scanner is controlled using a laptop or tablet with a set of programs, or using the touch control panel built into the scanner. 


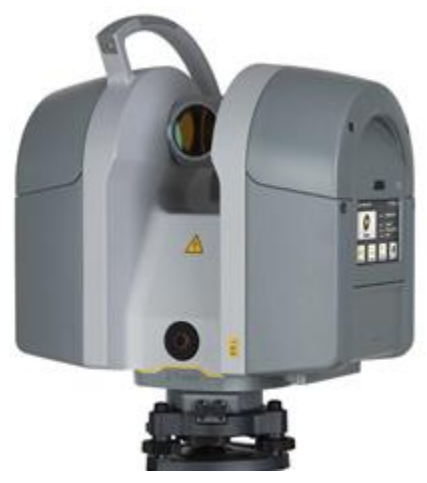

Fig. 9. Laser scanner Trimble TX8.

The software products used in laser scanning technology can be divided into groups:

1. Control software (setting the scanning resolution, scanning sectors by visual selection of objects, scanning mode, operating mode of a digital camera; visualization of scans in real time; control of the results obtained; identification of possible inaccuracies);

2. Software for creating a single point model (combining scans; external orientation of scans; visualization of a point model);

3. Software for building three-dimensional models and two-dimensional drawings from scan data (creating a model of a scanned object using geometric simple objects; building drawings; taking measurements: lengths, diameters, areas and volumes of objects; visualization of the constructed model);

4. Complex software (all functions of the control software; creation of a point model; construction of three-dimensional models and two-dimensional drawings based on the data of ground laser scanning).

Three-dimensional scanning of objects gives an opportunity to create digital models not only of individual buildings and structures, but also of entire complexes or territories. With its help, it is possible to get refined data when working with complex architectural forms. This allows the method to be widely used for the restoration and restoration of architectural monuments. When restoring a building, it is necessary to control the reconstruction process, which is effective using this method. It gives a possibility to obtain a digital model of the structure at each stage with high accuracy.

\section{Restoration of architectural complexes and laser scanning of structures}

When laser scanning complex architectural forms, certain difficulties arise with the automatic transfer of data into computer modeling programs. This is due to the fact that most of these applications describe the buildings with only the simplest geometric shapes. This means that when modeling architectural monuments, it is necessary to transfer the data obtained during ground scanning manually. To get a complete picture, the work of a specialist who can choose the right points for shooting and plan scanning sessions should be performed, and it is also necessary to involve other methods of collecting information about the object. For instance, to use scanning from the air, photography and aerial photography, mobile scanning. And of course, we must not forget about the traditional collection of information: historical documents, drawings, photos and video files.

If the destruction has occurred recently, then for the restoration process witnesses who saw this object intactare involved. This is exactly what is done when restoring the objects of architectural heritage in Damascus and Aleppo in Syria (Fig. 10). But to restore Palmyra, 
it is necessary to involve all possible methods of collecting information to build a 3D model of the object, since restoration work is needed there, practically from scratch (Fig. 5). And only then carefully create an architectural complex that closely reminds us of a real object before destruction.

The example is the process of rebuilding the city of Herat in Afghanistan. Throughout the long history of this city, Herat came under the influence of various Central Asian empires, but remained a center of science, culture and trade. The massive fortifications of the citadel (Fig. 8) and the Jami Friday Mosque (Fig. 11), which is 800 years old, are the main structures of the old city. The Great Cathedral Mosque in Herat (Jami Friday Mosque) is known as a world architectural heritage site. When the complex ornament of the mosaic facing was restored, the old mosaic workshops were specially restored (Fig. 12). The work has been in progress since 1943 and lasted for quite a long time. During the restoration process, it was possible to preserve the original appearance of the mosquesouthern portal.

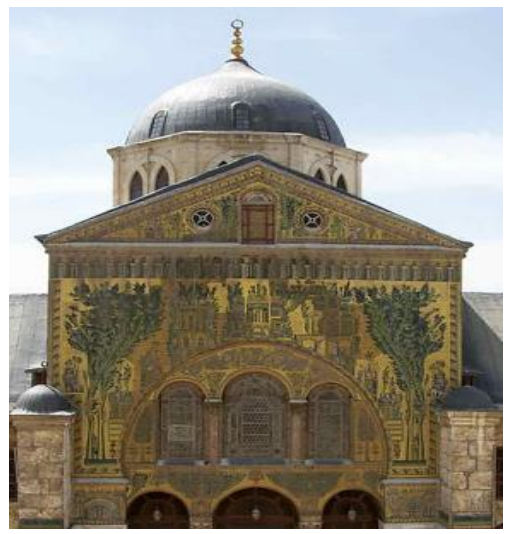

Fig. 10. Mosaic veneer in the Umayyad Mosque, Damascus (Syria)

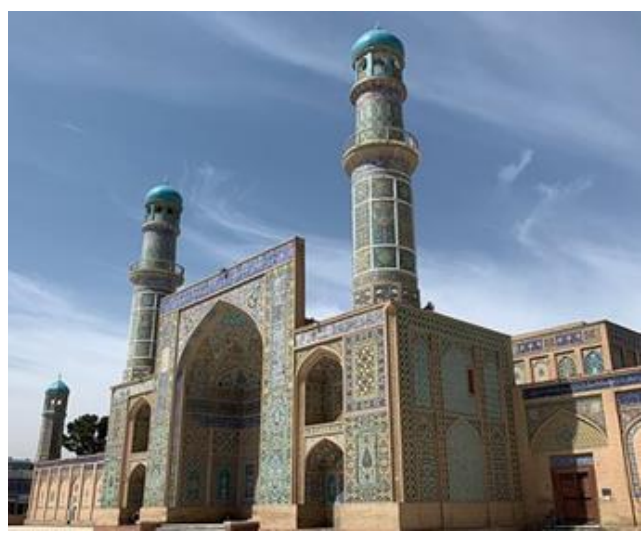

Fig. 11. Great Cathedral Mosque in Heart (Friday Jami Mosque), Afghanistan.

It is rather difficult to carry out automatic laser scanning of architectural elements of a mosque with a fractal surface $[16,17]$. It is necessary to conduct a comprehensive survey of such structures. Fig. 12-15 show fractal surfaces that are difficult to scan. But to preserve it, it is nevertheless necessary to create a digital library using three-dimensional modeling methods, especially for those objects where the political situation is unstable and there is a likelihood of military conflicts.

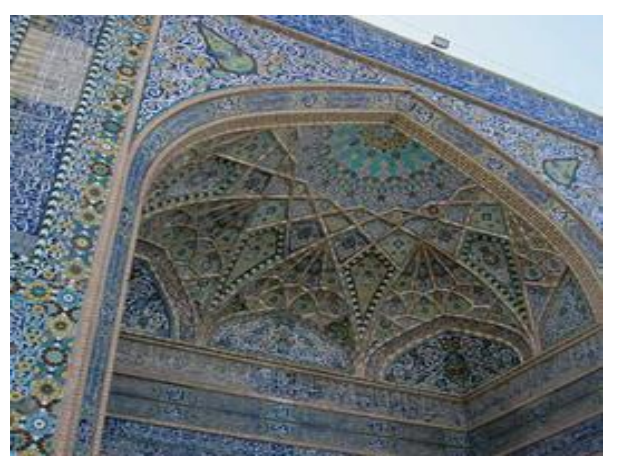

Fig. 12. Mosaic facing of the Great Cathedral Mosque, Herat, (Afghanistan).

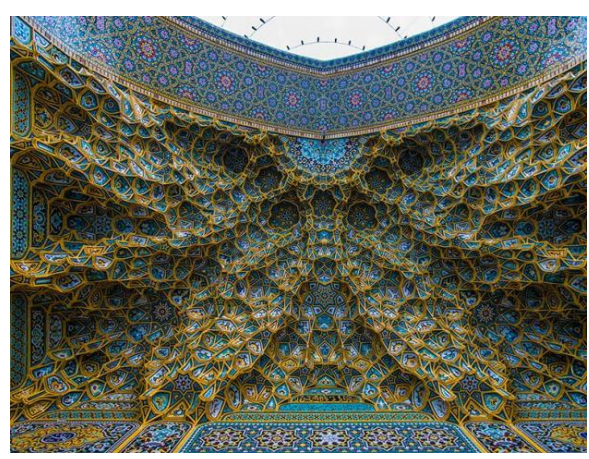

Fig. 13. Mosaic facing in the Jamila Hayan mosque, Mashhad (Iran). 


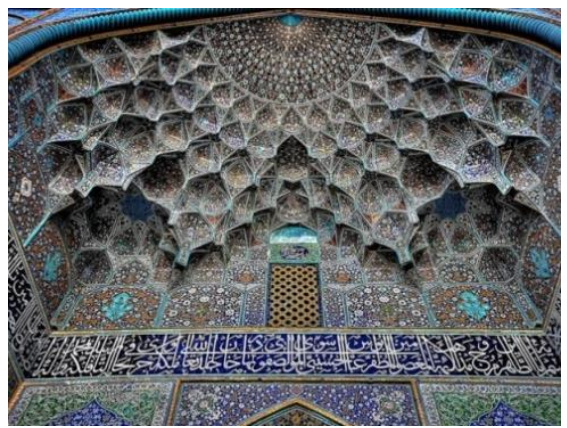

Fig. 14. Mosaic cladding in Sheikh Lutfalla Mosque, Isfahan, (Iran).

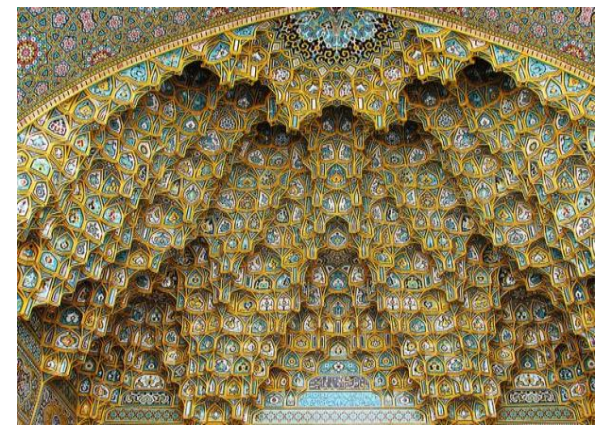

Fig. 15. Mosaic cladding in the Fatima Masumeh Mosque, Qom (Iran).

Although laser scanning of buildings and structures is not a fully automatic procedure, it avoids many time-consuming tasks and takes complex measurements at a touch of a button. But the latest recovery and analysis techniques can include a wide variety of technologies. For example, the method of scanning laser vibrometry makes it possible to reveal the hidden defects and mechanical stresses inside a monument of art [18-22]. It is necessary to actively introduce innovations into the practice of restoration and preservation of objects of architectural heritage.

\section{Conclusion}

The urgency and importance of the architectural complexes restorationproblem in modern conditions is determined by the dangerous tendency of their destruction as a result of military conflicts. Such destruction and irreversible loss of architectural structures'elements leads to the fact that future generations can only partially see these objects, and then only in photographs and in video materials. Architects all over the world agree that the buildings of the world architectural heritage must be seen in reality and the historical past must be remembered. It is a wide-spread opinion, that there is no future without the past. All these architectural monuments are the property of all mankind. And they must also be saved by joint efforts.

Today, there are a number of innovative technologies that can be applied in the restoration of structures and architectural elements. For example, there are threedimensional modeling technologies that can replace the usual architectural measurements. They provide more accurate geometry of elements of any size and complex shape, which allows digital copying of architectural objects. The resulting 3D models can be easily stored for subsequent restoration, it is possible to make cartograms of monuments indicating all defects, the position of fasteners and create files with other necessary information.

These technologies require full-fledged three-dimensional modeling of objects by different methods and for different projects. These include support for information modeling- BIM of buildings and structures, facade surveys, digital drawings of structures and objects of architectural heritage. With the advent and development of laser scanning technology, the task of building 3D digital models has become much easier.

\section{References}

1. V.P. Maksakovskiy, World cultural heritage (Peter Publishing, 2002).

2. H. Stierlin, Encyclopaedia of world architecture, (Evergreen Publishing, 1994). 
3. Eugène Emmanuel Viollet-le-Duc, Architecture. World history of architecture, (Publishing AST, 2018).

4. P.P. Gnedich, World architecture (Eksmo-PressPublishing house, 2012).

5. Ya. Stankova, I. Pekhar, Millennial development of architecture (Stroyizdat Publishing, 1984).

6. B.V. Veymarn, Art of the Arab countries and Iran of the 7th-17th centuries, (Art Publishing, 1974).

7. V.N. Kartsev, The architecture of Afghanistan (StroyizdatPublishing, 1986).

8. M. Murray, Egyptian temples (Zentrpolygraph Publishing, 2006).

9. J.D. Hoag, Islamic architecture (Electa architecture Publishing, 2004).

10. T. Starodub-Enikeeva, Treasures of Islamic Architecture (Publishing Belyi Gorod, 2004).

11. M.A. Polyakova, Protection of cultural heritage in Russia (Publishing Drofa, 2005).

12. S.S. Podyapolsky, G.B. Bessonov, L.A. Belyayev, T.M. Postnikova, Restoration of architecture (Stroyizdat Publishing, 1988).

13. Mikhailovsky, Restoration of architectural monuments (Stroyizdat Publishing, 1971).

14. A.B. Aleshin, N.G. Bregman, Yu.G. Bobrov, Restoration of monuments of history and art in Russia in the XIX-XX centuries. History, problems (Academic Project Alma Mater Publishing, 2015).

15. A.A. Kedrinskiy, Fundamentals of the restoration of architectural monuments. Generalization of the experience of the school of Leningrad restorers (Art Publishing, 1999).

16. S.B. Yazyeva, I.A. Mayatskaya, I.V. Kashina, A.N. Nesterova, Materials Science and Engineering 698 (3), 033046 (2019).

17. B.M. Yazyev, I.A. Mayatskaya, S.B. Yazyeva, S.B. Yazyev, Materials Science and Engineering 698 (2), 022087 (2019).

18. S.F. Nikolayev, Young scientist 14 (304), 268-270 (2020).

19. A.I. Uskreev, Business and design review 2 (18), 12 (2020).

20. A.S. Shcheglov, A.A. Shcheglov, Engineering restoration of architectural monuments, (Publishing ASV, 2015).

21. A.S. Kolodyazhny, V.L. Mishchenko, A.S. Shcheglov, A.A. Shcheglov, Engineering research of architectural monuments (Publishing ASV, 2018).

22. A.S. Shcheglov, A.A. Shcheglov, Diagnostics of the cultural heritage objects' technical condition (Infra-Engineering Publishing, 2019). 